\title{
PURIFICATION OF LANDFILL LEACHATE WITH THE REVERSE OSMOSIS AND NANOFILTRATION MEMBRANE PROCESS - PRACTICAL EXPERIENCES AND RESULTS WITH REGARD TO APPLICATIONS IN SCANDINAVIA
}

\author{
Hartmut Eipper \\ Pall GmbH Wassertechnik, Germany
}

Bengt de Vylder Larsen

ETECH Process AS, Norway

\begin{abstract}
The most important membrane process for purification of landfill leachate is reverse osmosis. With this technology the negative impact of leachate on the environment can be nearly fully eliminated. The first large-scale plants went into operation in the mid eighties. Today, approximately one third of the installed capacity worldwide bases on this technology.
\end{abstract}

Based on experiences with numerous systems which have been in operation for many years, results concerning the main parameters such as COD, ammonia etc. are presented. Depending on how the permeate is discharged, either directly into a surface water or indirectly into a municipal sewage treatment plant (i.e. RO works as pre-treatment), excellent quality parameters for the permeate may be achieved.

With such systems working within a pressure range up to 65 bar, recovery rates between $65 \%$ and $80 \%$ permeate may be achieved with leachates with normal salt concentrations.

In order to achieve higher recovery rates, the treatment of landfill leachate by RO has been significantly improved by the introduction of high-pressure osmosis. This results in a minimised concentrate amount which considerably eases disposal. The utmost reduction of concentrate is achieved in the additional combination with nanofiltration which may yield a recovery rate of more than $90 \%$.

The application of nanofiltration makes sense for the concentration of such leachates where not the osmotic pressure due to high salt concentration but the presence of 
KALMAR ECO-TECH'03

Bioremediation and Leachate Treatment

KALMAR, SWEDEN, November 25-27, 2003

membrane sealing factors such as earth alkaline ions limit the recovery rate. Nanofiltration selectively retains two or more valent ions and thus enables high concentration factors to be achieved.

For Scandinavian applications with dilute leachate simpler concepts with single stage units have been realized. By demonstration and commercial size applications it could be proven that such membrane systems are suitable for purifying high amounts of leachate with low concentration of salt and organic components.

\section{INTRODUCTION}

The demands of the EU council directive 1999/31/EU dated April $26^{\text {th }} 1999$ make the treatment of landfill leachate compulsory in all member countries.

An evaluation of the data for the leachate from a large number of landfills shows, that the amount of components dissolved in leachate from different kinds of landfills covers the range from 2 to $15 \mathrm{~g} / \mathrm{l}$ (figure 1 ).

\begin{tabular}{|l|l|}
\hline $\mathrm{m}^{3} / \mathrm{ha} / \mathrm{d}:$ & $0,5-40$ \\
\hline
\end{tabular}

\begin{tabular}{|l|cl|}
\hline COD & $200-10.000$ & $\mathrm{mg} / \mathrm{l}$ \\
\hline BOD & $10-5.000$ & $\mathrm{mg} / \mathrm{l}$ \\
\hline AOX & $0,1-7$ & $\mathrm{mg} /$ \\
\hline $\mathbf{N H}_{4}{ }^{+}-\mathbf{N}$ & $50-4.000$ & $\mathrm{mg} /$ \\
\hline Conductivity & $2.000-30.000$ & $\mu \mathrm{S} / \mathrm{cm}$ \\
\hline Sulfate & $30-8.000$ & $\mathrm{mg} / \mathrm{l}$ \\
\hline Chloride & $300-10.000$ & $\mathrm{mg} / \mathrm{l}$ \\
\hline
\end{tabular}

Figure 1. Parameter and Volumes European Leachate

Since such contaminants are mostly not appropriate for treatment by conventional biological processes, new regulations tend to limit the discharge of such complex wastes to municipal sewers. Even by combining biological treatment with adsorption by active carbon or with the oxidation of part of the dissolved organic material using ozone or other oxidizing agents, only partial destruction of contaminants will be achieved. It will not reach the purification needed to fully reduce the negative impact of landfill leachate on the environment. One aspect is the so called "hard COD" that is not biodegradable and cannot be destroyed or adsorbed sufficiently. Thus it remains in the water discharged after being treated with the mentioned processes, causing problems in the future as a consequence of the effects of long time accumulation. 
Another type of compound not available for digestion by micro organisms within the time of contact in biological treatment plants are the halogenated hydrocarbons (e.g. $\mathrm{AOX}=$ Absorbable Organic Halogenated Compounds regulations).

For this reason, in several countries discharge into a sewer (indirect discharge) is only permitted, if these parameters do not exceed specific limitations. Combined treatment in municipal sewage treatment plants just result in dilution instead of purification (figure 2).

\begin{tabular}{|c|c|c|c|c|c|c|c|c|c|}
\hline \multirow[t]{2}{*}{ Parameter } & \multirow[t]{2}{*}{ Unit } & \multicolumn{2}{|c|}{ Germany } & \multicolumn{2}{|l|}{ Austria } & \multicolumn{2}{|c|}{ Netherlands } & \multirow{2}{*}{$\begin{array}{l}\text { Spain } \\
\text { Direct }\end{array}$} & \multirow{2}{*}{$\begin{array}{l}\text { Italy } \\
\text { Direct }\end{array}$} \\
\hline & & $\begin{array}{l}\text { Dire } \\
\text { ct }\end{array}$ & \begin{tabular}{|l} 
Indire \\
ct
\end{tabular} & Direct & Indirect & Direct & Indirect & & \\
\hline $\mathrm{PH}$ & & - & - & $6,5-8,5$ & $6,5-9,5$ & $6,5-9,0$ & $6,5-9,0$ & $5,5-9,5$ & $5,5-$ \\
\hline Conductivity & $\mu \mathrm{s} / \mathrm{c}$ & - & - & - & - & - & - & & 9,5 \\
\hline $\begin{array}{l}\text { Suspended } \\
\text { solids }\end{array}$ & $\begin{array}{l}\mathrm{m} \\
\mathrm{mg} / \mathrm{l}\end{array}$ & - & - & 20 & - & - & - & 80 & - \\
\hline COD & $\mathrm{mg} / \mathrm{l}$ & 200 & 400 & 50 & - & 100 & - & 160 & 160 \\
\hline BOD & $\mathrm{mg} / \mathrm{l}$ & 20 & - & 10 & - & 20 & - & 40 & 40 \\
\hline AOX & $\mathrm{mg} / \mathrm{l}$ & 0,5 & 0,5 & 0,5 & 0,5 & - & - & - & - \\
\hline$\sum$ Hydrocarbons & $\mathrm{mg} / \mathrm{l}$ & 10 & - & 5 & 15 & - & - & - & - \\
\hline arom. HC, BTX & $\mathrm{mg} / \mathrm{l}$ & - & - & 0,1 & 0,5 & 0,005 & 0,3 & - & - \\
\hline Phenolindex & $\mathrm{mg} / \mathrm{l}$ & - & - & - & - & - & - & 0,5 & - \\
\hline Aldehydes & $\mathrm{mg} / \mathrm{l}$ & - & - & - & - & - & - & 1 & - \\
\hline Detergents & $\mathrm{mg} / \mathrm{l}$ & - & - & - & - & - & - & 2 & 2 \\
\hline Pesticides & $\mathrm{mg} / \mathrm{l}$ & - & - & - & - & - & - & 0,05 & - \\
\hline
\end{tabular}

Figure 2. Discharge Limits (Organics and Conductivity)

Therefore more effective methods of treatment of this material have had to be developed. The use of reverse osmosis either as a main step in a landfill leachate treatment chain or as a single step has shown to be a very successful way for achieving full purification.

\section{APPLICATION OF REVERSE OSMOSIS}

With the reverse osmosis the leachate to be treated is split by a membrane into a partial stream of purified permeate and into residual water respectively concentrate (figure 3 ). 


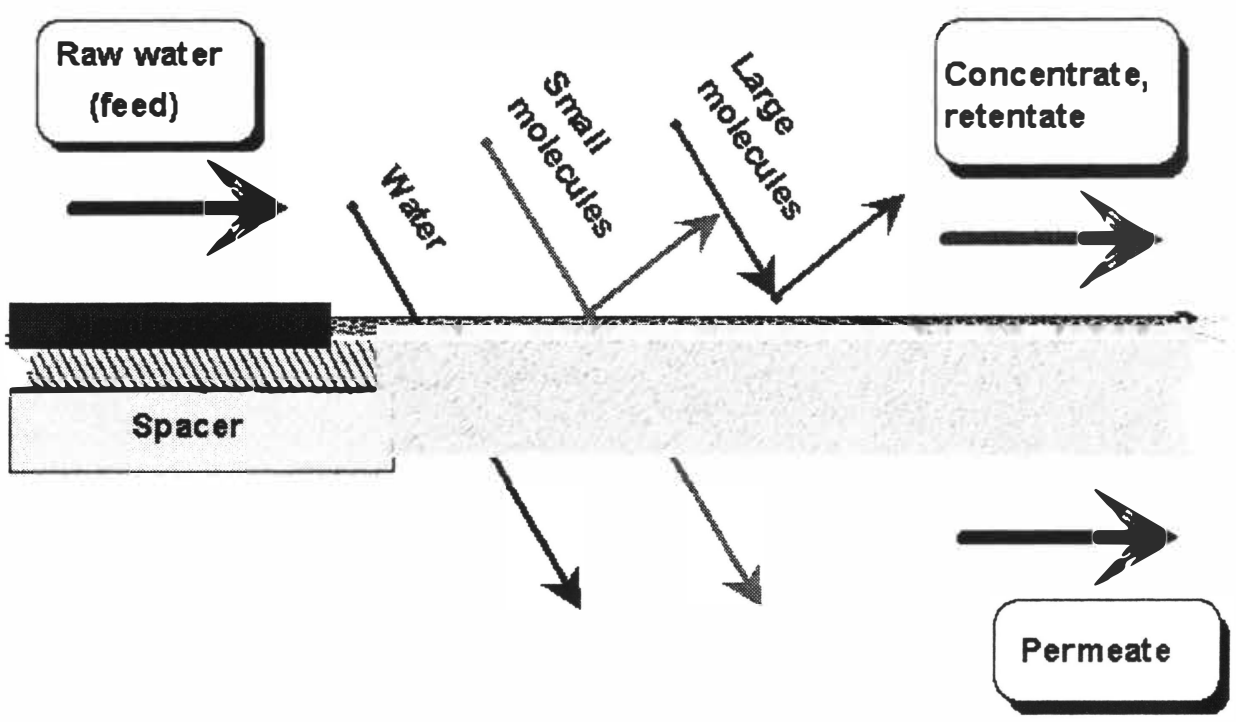

Figure 3. Principle of Separation

Due to the ability of modern high-rejection reverse osmosis membranes to retain both organic and inorganic contaminants dissolved in water at rejection rates of $98-99 \%$, reverse osmosis is also useful for purifying liquid waste such as landfill leachate and for helping to solve the growing problem of water pollution (Peters, 1996).

On the feed-water side of the membrane, the dissolved organic and inorganic contaminants are concentrated in the retentate, whereas the pure water is pressed through the membrane. Consequently with the reverse osmosis membrane a treated water stream the permeate - is generated, which contains only very low levels of inorganic and organic contaminants.

As the salts are concentrated in the retained part of the liquid, the osmotic pressure has to be overcome. Therefore, special pumps must apply enough pressure to the raw water to exceed the sum of osmotic pressure and pressure losses (figure 4). 


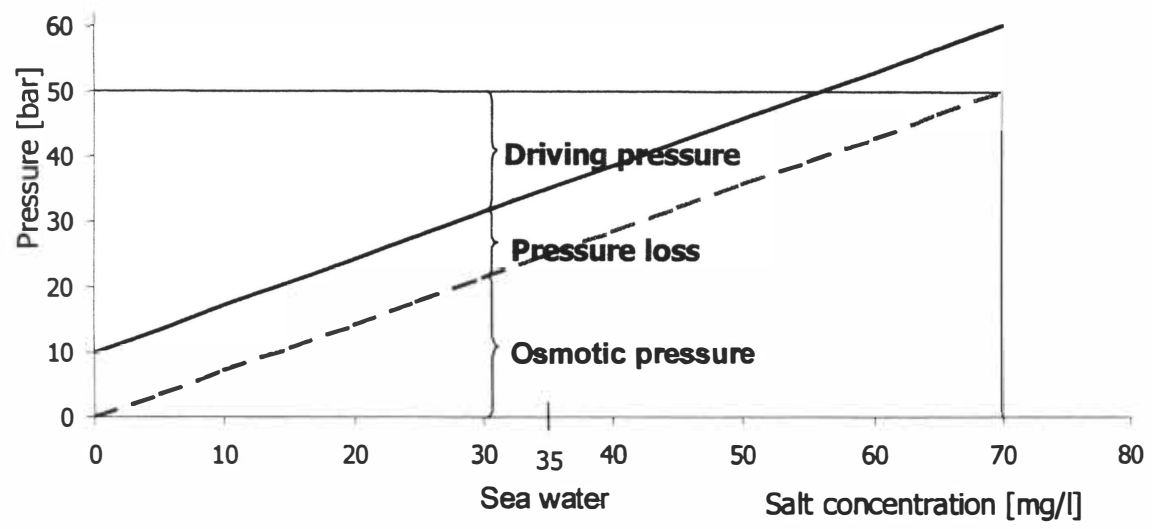

Figure 4. Relation between Salt Concentration and Pressure

As the reverse osmosis membranes function as barriers, the purification process can be monitored reliably by easy on-line measurement of electric conductivity. Start up and shut down of plants are initiated by pressing a button and performance is achieved within a couple of minutes. Because of the high rejection rate for each kind of contaminant dissolved in the feed water the system shows a high flexibility against changes of the concentration of the compounds in the leachate.

The modules have to be able to be cleaned with high efficiency to prevent scaling, fouling and biofouling of the membranes. To achieve this goal reliably the use of modules with open channels is an indispensable condition.

In the beginning of landfill leachate purification tubular modules were the first module type used in 1984. An alternative - the disc-tube (DT-) module (figure 5) - was introduced to this market in 1988. Since then more than 100 systems have been installed with great success. Meanwhile this module type constitutes by far the leading technology with the main market share for RO-treatment of leachate (Eipper, 1999).

\section{Permeate}

Figure 5. The DT-
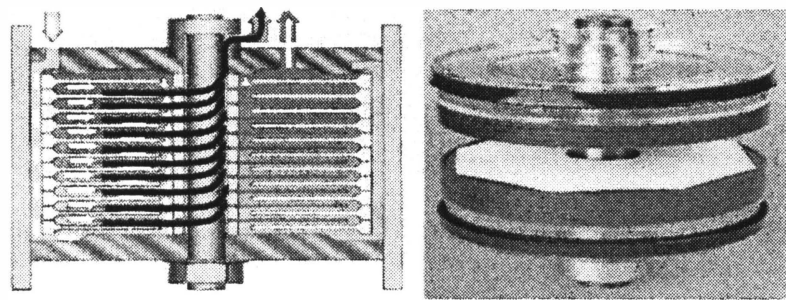


\section{THE TREATMENT SYSTEM}

Whereas for indirect discharge a single stage system is normally sufficient, for direct discharge a double stage unit is needed, mainly for the removal of ammonia.

Cleaning devices, acidification for decreasing $\mathrm{pH}$ to approx. 6.5 and permeate degasification accomplish the technical system. In-line pump technology ensures an equal flow velocity through the modules. With such design, permeate recovery rates between 70 and $80 \%$ are feasible (figure 6).

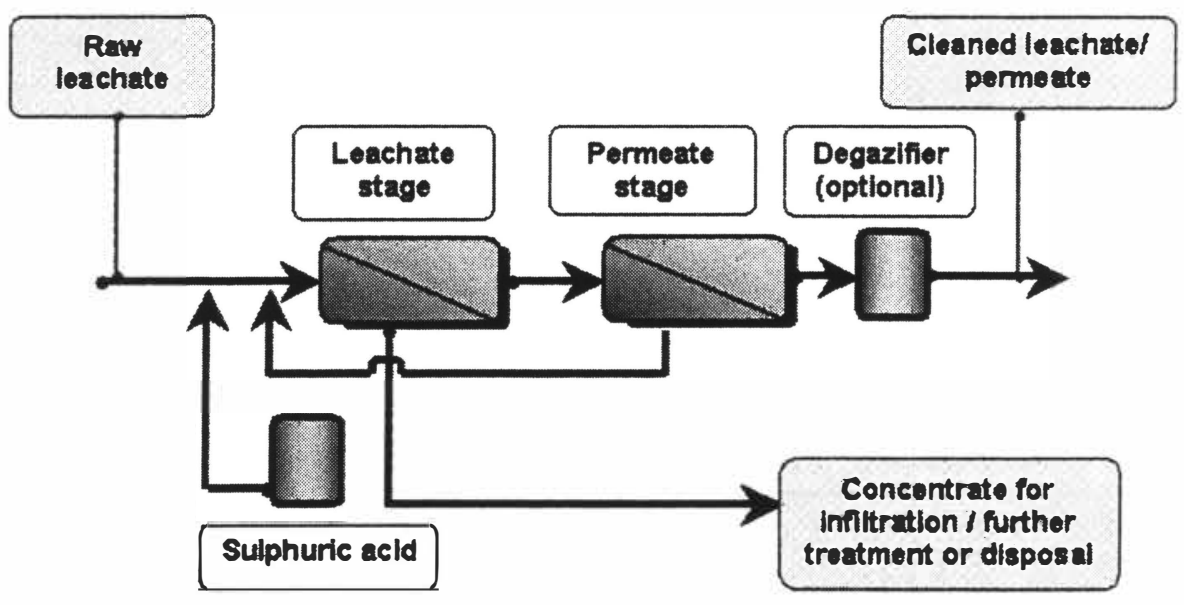

Figure 6. Process flow sheet -2 stages

For this type of systems a pressure range up to 65 bar is usually applied. Depending on the initial conductivity of raw leachate, $50.000-60.000 \mu \mathrm{S} / \mathrm{cm}$ may be achieved in the concentrate.

Examples are given in pictures 7 and 8.

- $\quad 36 \mathrm{~m}^{3} / \mathrm{d}$ system in Italy, installed in a lightweight building, recovery rate $75 \%$, infiltration of concentrate (figure 7)

- $\quad 30 \mathrm{~m}^{3} / \mathrm{d}$ system in Germany, all components including tank system installed in one $20 \mathrm{ft}$-container, recovery rate $80 \%$, external disposal of concentrate (physical-chemical treatment) (figure 8)

- $\quad 90 \mathrm{~m}^{3} / \mathrm{d}$ system on a trailer, for varying operation (figure 8) 
KALMAR ECO-TECH'03

Bioremediation and Leachate Treatment

KALMAR, SWEDEN, November 25-27, 2003

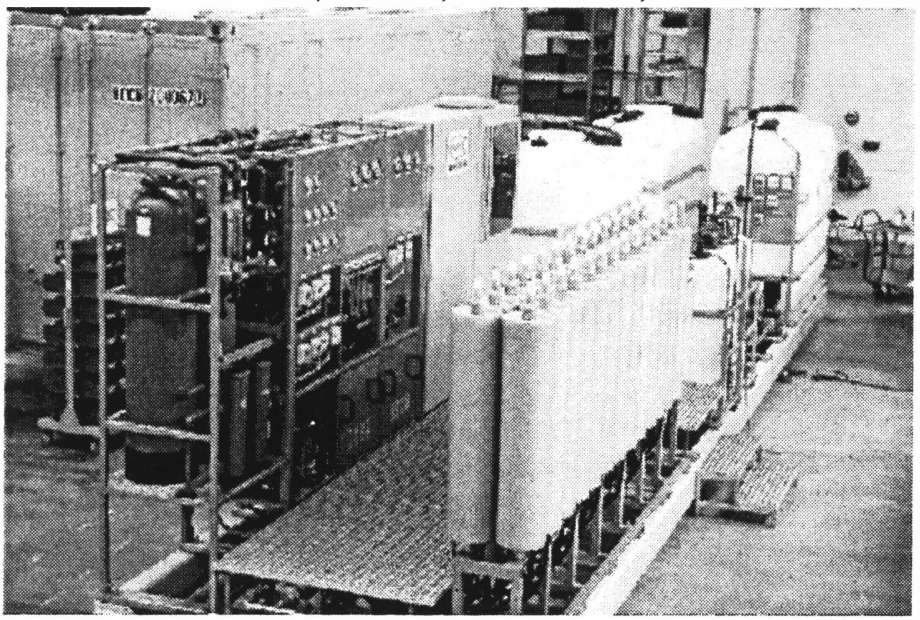

Figure 7. Purification Plant "Piombino"

$$
\mathrm{Q}_{\mathrm{d}}=90 \mathrm{~m}^{3} / \mathrm{day}
$$
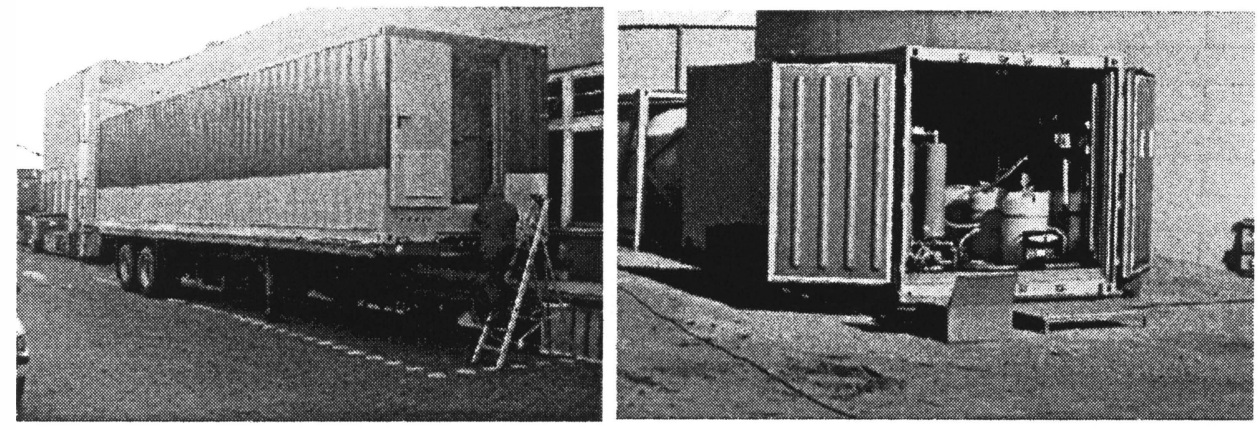

$$
\mathrm{Q}_{\mathrm{d}}=30 \mathrm{~m}^{3} / \mathrm{day}
$$

Figure 8. Mobile Leachate Treatment Plants 


\section{HIGH PRESSURE RO}

Because of an additional development of the successful DT-module the pressure range up to 65 bar could be extended to 120 bar in a first step and 150 bar in a second step (figure 9). With that the technical limitations given so far for the concentration of leachate could be exceeded and increased up to the double value (Reese, 1998). This equals an extension of the total permeate output from the maximum of $80 \%$ which is achievable in the leachate treatment technology (equal to a concentration factor of 5) up to $90 \%$ output with a corresponding concentration of the leachate components in the retentate by a factor 10. Using operation pressure of 120 bar a conductivity of 100000 to $120000 \mu \mathrm{S} / \mathrm{cm}$ can be attained. This results in another reduction of volume of the concentrate to be disposed.

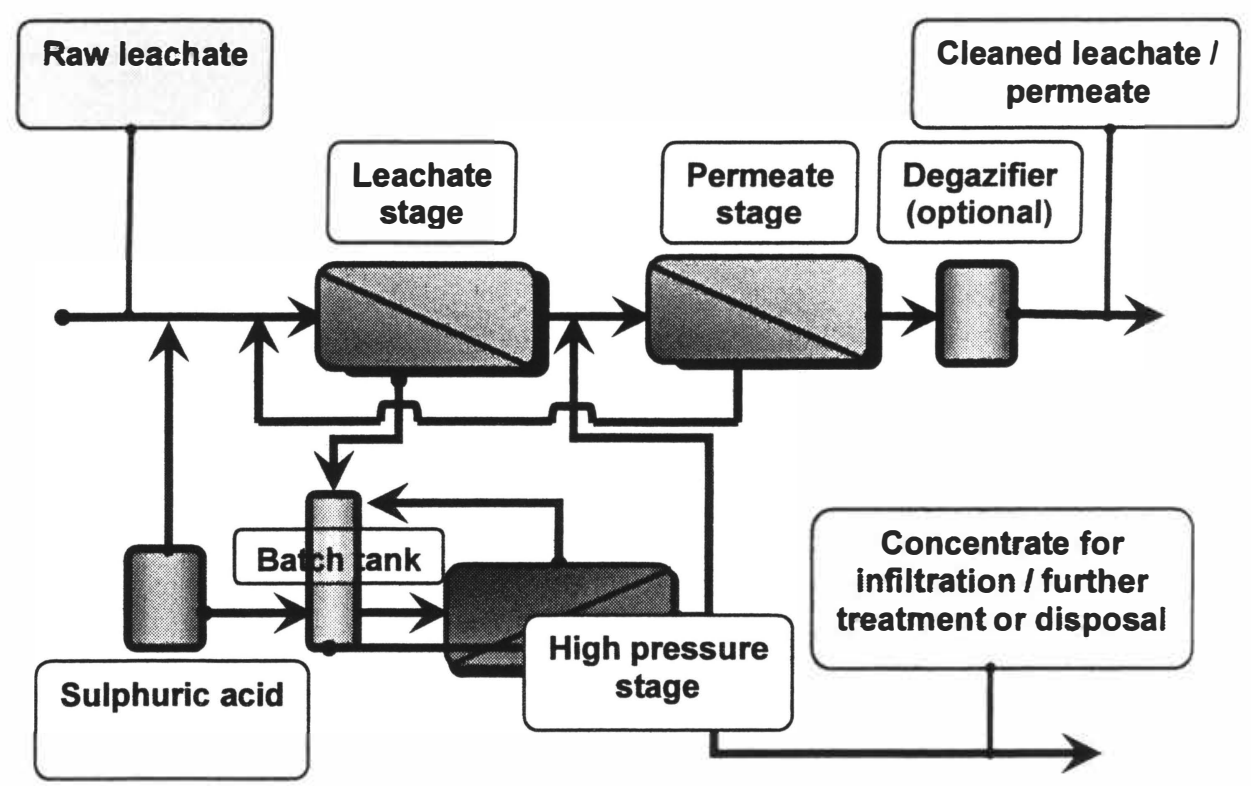

Figure 9. Multiple Stage RO with High Pressure Stage

The concentration factor which is needed depends strongly on the way of concentrate disposal (figure 10). For controlled infiltration $70-75 \%$ recovery (concentration factor 4 ) is sufficient. However, for drying or incineration a maximum concentration factor is desirable (Hanashima, 1999). 
- Physical - Chemical Treatment

- Solidification

- Incineration

- Evaporation / Drying

- Controlled Infiltration into Landfill

Figure 10. Disposal of Concentrates

\section{NANOFILTRATION}

For indirect discharge (into a municipal sewage treatment plant) sometimes COD and organic halogenated components are the only crucial parameters, as ammonia is well removed by biological treatment and conductivity may not be limited. In such cases nanofiltration may replace RO. As retention rates are much lower that with RO this technology may be applied with moderate values in raw leachate only (figure 11).

\begin{tabular}{l|r} 
Parameter & Retention [\%] \\
\hline Conductivity & $40-60$ \\
COD & $85-90$ \\
AOX & $75-85$ \\
Ammonia & $<20$ \\
Heavy Metalls & $>90$
\end{tabular}

Figure 11. Retention Rates of Nanofiltration

\section{EXAMPLE FOR RESULTS}

The barrier function of the membrane and the high retention rates for all types of contaminants ensure a stable operation with high efficiencies, such as e.g. in landfill Hasenbühl (Germany).

- Conductivity decrease, so that the permeate may be used for irrigation and similar demanding applications (figure 12)

- COD removal of more than 99\%; all toxic material and "hard COD" are removed from the permeate (figure 13)

- $\quad \mathrm{NH}_{3}$ removal of more than $98 \%$ (figure 14 ) 
KALMAR ECO-TECH'03

Bioremediation and Leachate Treatment

KALMAR, SWEDEN, November 25-27, 2003

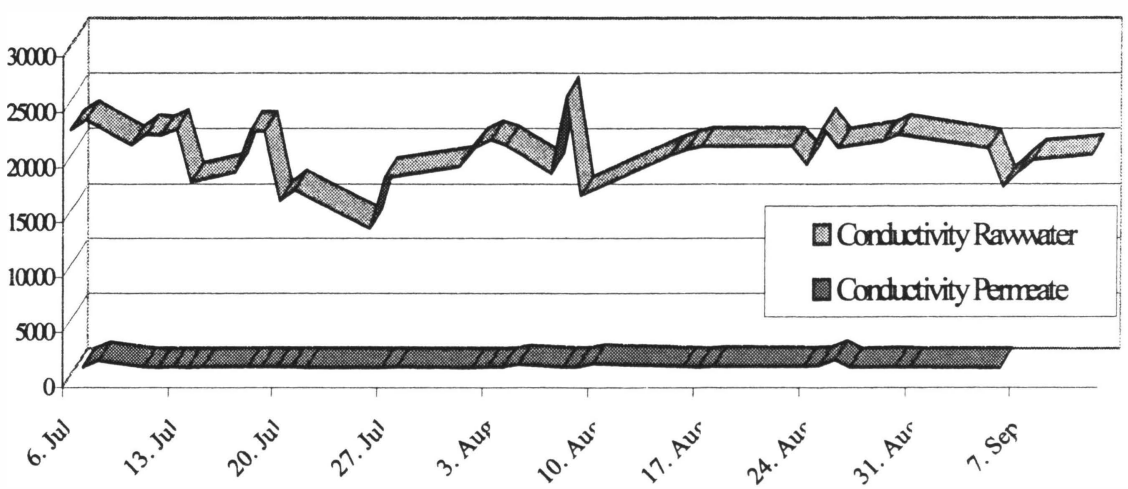

Figure 12. Conductivity Decrease

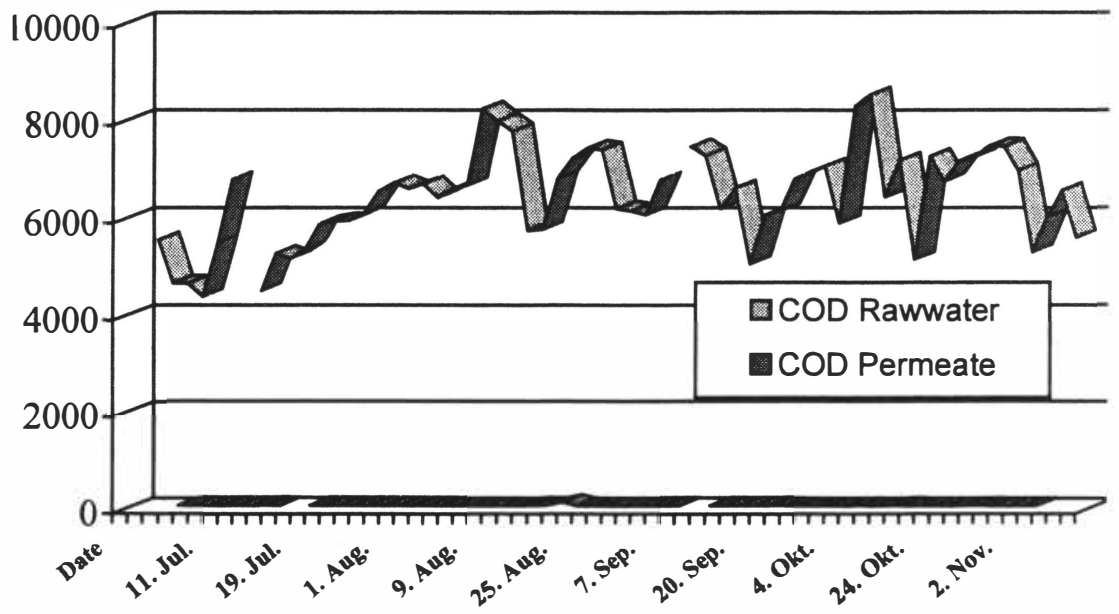

Figure 13. COD Removal 
KALMAR ECO-TECH'03

Bioremediation and Leachate Treatment

KALMAR, SWEDEN, November 25-27, 2003

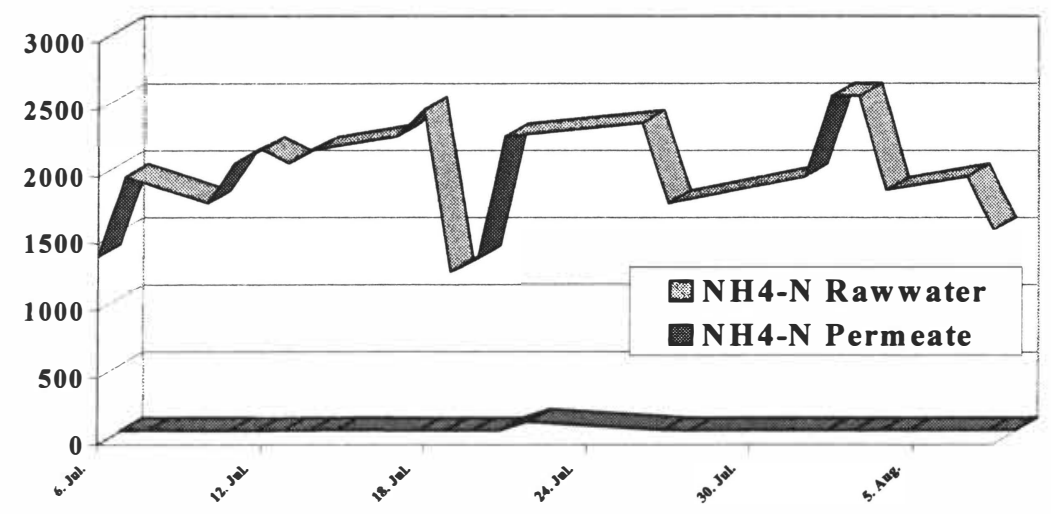

Figure 14. Ammonia Reduction

\section{RESULTS FROM TRIALS IN NORWAY}

For utilisation of RO-technology in Scandinavian countries some special leachate properties - due to climate conditions - have to be considered. This refers mainly to leachate amounts (relating to landfill size) and accordingly to concentration of components as the leachate is more diluted than in Central or Southern Europe.

When the town of Molde in Norway considered treatment of leachate of their municipal landfill, it was therefore decided to carry out trials on demonstration scale first. The leachate in Molde is characterized by the following main parameters:

$\begin{array}{ll}\mathrm{pH} & 6,5-7 \\ \text { conductivity } & 5.000-9.000 \mu \mathrm{S} / \mathrm{cm} \\ \mathrm{COD} & 1.500-3.200 \mathrm{mg} / \mathrm{l} \\ \mathrm{NH}_{4}-\mathrm{N} & 200-400 \mathrm{mg} / \mathrm{l} \\ \mathrm{Fe} & 10 \mathrm{mg} / \mathrm{l}\end{array}$

Conductivity is in the usual range, where as ammonia is fairly low. Iron, however, is found to be considerably high. This effect was found at other sites in Scandinavia as well. $\mathrm{pH}$ is in a low range.

Because of the low ammonia concentration it was expected that a sufficient purification rate should be achieved with a single stage unit already.

The demonstration unit was installed at site in winter 2002/03. It comprised a complete unit with tank system in a $20 \mathrm{ft}$. container and two storage containers (figure 15). 


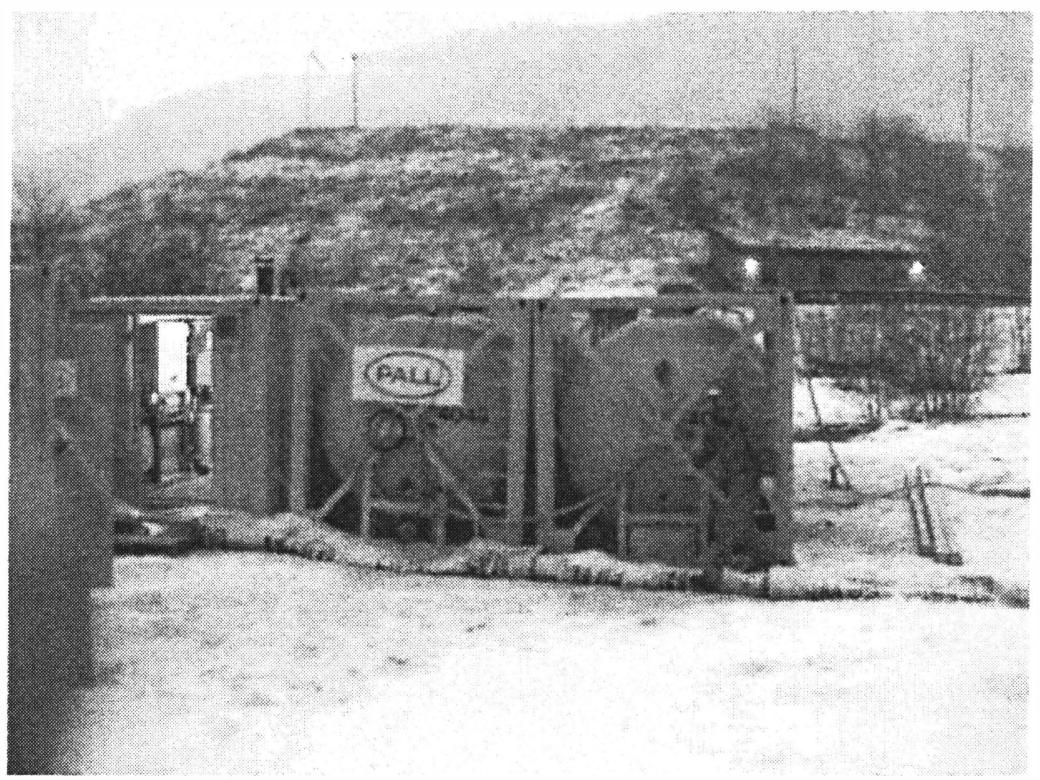

Figure 15. Demonstration system Molde

This system was able to receive $1,5 \mathrm{~m}^{3} / \mathrm{h}$ of raw leachate and to yield $75-80 \%$ permeate recovery. The results, which were achieved, were very satisfactory. They are shown in figure 16. 
KALMAR ECO-TECH'03

Bioremediation and Leachate Treatment

KALMAR, SWEDEN, November 25-27, 2003

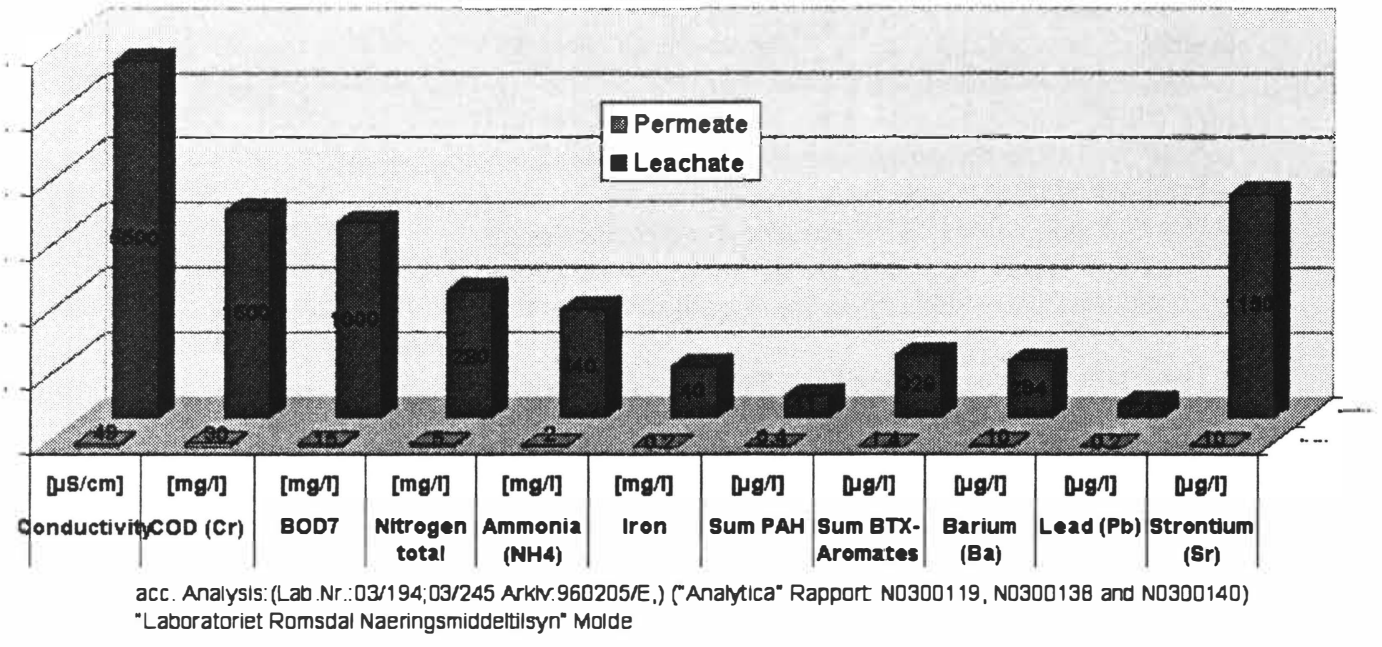

Figure 16. Leachate Molde - retention values

The calculated reduction rates are correspondingly high (figure 17).

Figure 17. Leahate Molde-reduction rates

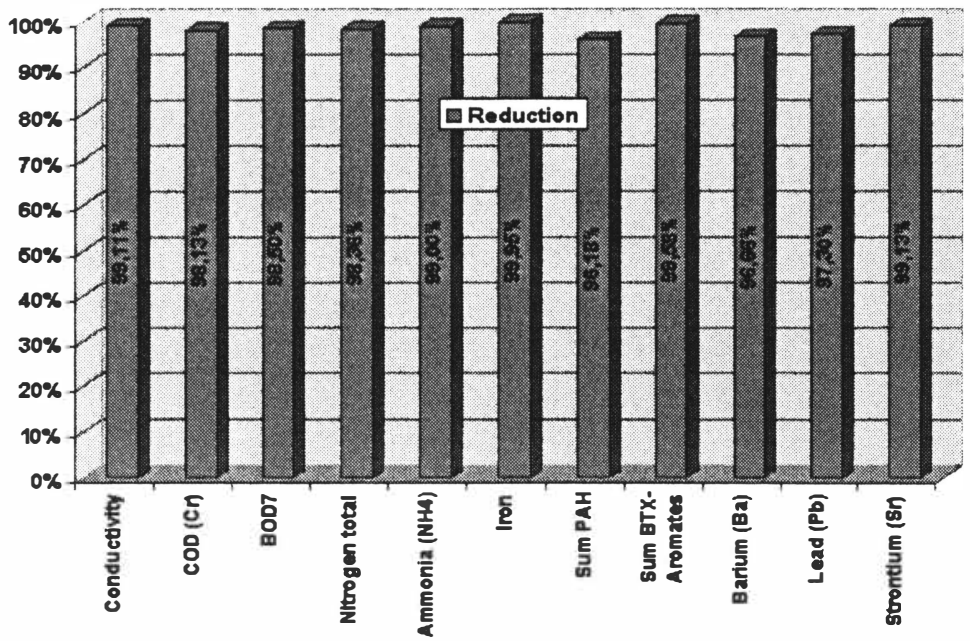


KALMAR ECO-TECH'03

Bioremediation and Leachate Treatment

KALMAR, SWEDEN, November 25-27, 2003

The analytic results and the operational experiences of the demonstration trials led to the following conclusions:

1-stage unit sufficient

Low acid consumption

High iron oxide and solids load require settling before RO-treatment

Purification rates $>98 \%$

Heavy metals / PAH / BTX reduced to detection limit

RO meets all discharge limitations

Continuous and reliable operation feasible

These conclusions were the basis for the design considerations of a commercial size plant to meet the requirements of purifications:

This commercial system for a raw leachate input of $5 \mathrm{~m}^{3} / \mathrm{h}$ will be installed in late summer 2004. Another similar system for $13 \mathrm{~m}^{3} / \mathrm{h}$ leachate feed has been installed in NES municipality / Norway and is in commissioning phase.

Figure 18 shows a picture of this unit before shipping to site.

1-stage RO system

Leachate storage basin / tank required

Adjustment for low temperature conditions

(heat inputt/ membrane area)

Alkalinet/ acid cleaning required (iron oxide removal)

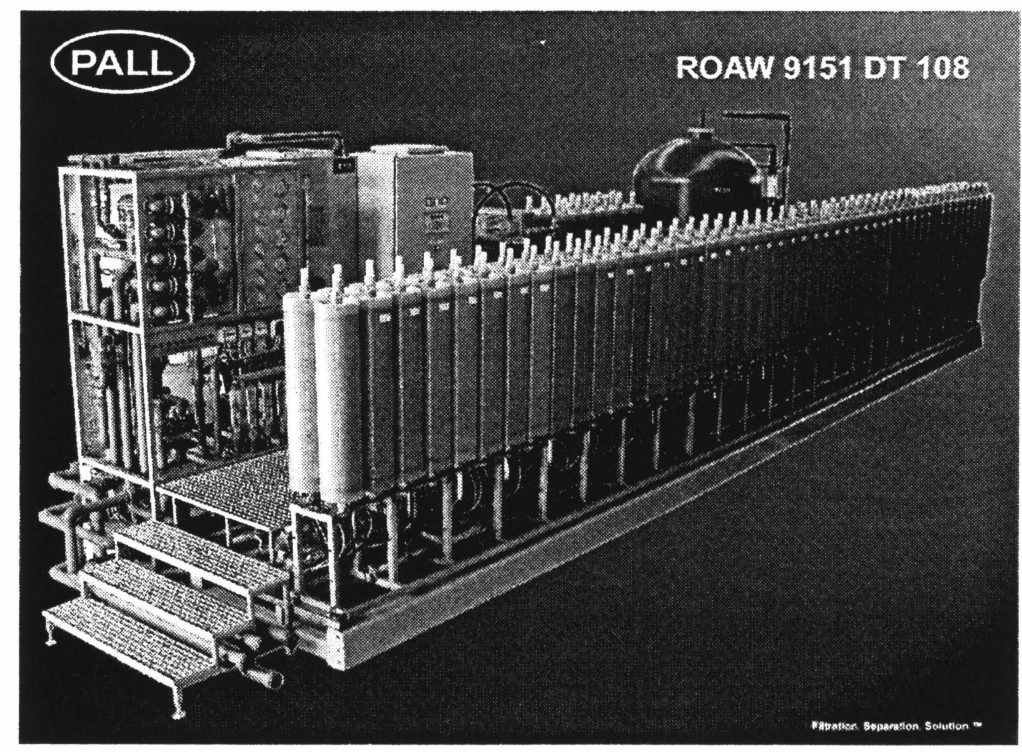

Figure 18. System NES / Norway 


\section{SUMMARY}

The most important membrane process for purification of landfill leachate is reverse osmosis. With this technology the negative impact of leachate on the environment can be nearly fully eliminated. The first large-scale plants went into operation in the mid eighties. Today, approximately one third of the installed capacity worldwide bases on this technology.

The application of nanofiltration for immediate leachate treatment is limited by the fact that salts and ammonia are not retained by this membrane. Thus it makes sense only in particular cases as pre-treatment.

Depending on how the RO-permeate is discharged, either directly into a surface water or indirectly into a municipal sewage treatment plant (i.e. RO works as pre-treatment), excellent quality parameters for the permeate may be achieved.

With such systems working within a pressure range up to 65 bar, recovery rates between $65 \%$ and $80 \%$ permeate may be achieved with leachates with normal salt concentrations. If concentrate disposal becomes crucial, such a recovery rate may not be enough. In order to overcome this impediment, the treatment of landfill leachate by RO has been significantly improved by the introduction of high pressure osmosis. This results in a minimised concentrate amount which considerably eases disposal.

Based on experiences with numerous systems which have been in operation for many years, the results concerning the main parameters such as COD, ammonia etc. demonstrate the performance of membrane technology for this application.

This applies for Scandinavian conditions as well as could be demonstrated by trials and first commercial applications in Norway.

\section{LIST OF FIGURES}

(1) Parameters and Volumes of European Leachate

(2) Discharge limits EU (Organics and Conductivity)

(3) Principle of Separation

(4) Relation between salt concentration and pressure

(5) The DT-Module

(6) Process flow sheet - 2 stages

(7) Purification plant "Piombino"

(8) Mobile Leachate Treatment Plants

(9) Multiple Stage RO with High Pressure Stage

(10) Disposal of concentrates

(11) Retention rates of NF

(12) Conductivity decrease

(13) COD Removal

(14) Ammonia reduction

(15) Demonstration system Molde 
KALMAR ECO-TECH'03

Bioremediation and Leachate Treatment

KALMAR, SWEDEN, November 25-27, 2003

(16) Leachate Molde - retention values

(17) Leachate Molde - reduction rates

(18) System NES / Norway

\section{REFERENCES}

[1] Eipper, H. \& Maurer C.: „Purification of Landfill Leachate with Membrane Filtration based on the Disc Tube DT"t, Proceedings SARDINIA 99, Seventh International Waste Management and Landfill Symposium, pp. 367-374, October 1999

[2] Hanashima M., Shimaoka T., Kobayashi T., Ushikoshi K., Suzuki H., Katsura K., Toji A. \& Kojima D., „Treatment of High Salinity Leachate by Reverse Osmosis and Development of Concentrate Treatment Technology", Proceedings SARDINLA 99, Seventh International Waste Management and Landfill Symposium, pp. 367-374, October 1999

[3] Peters, Th, „Volume Reduction of Leachate Concentrates with Modules for Nanofiltration and Reverse Osmosis“, Proceedings SARDINIA 95, Fifth International Waste Management and Landfill Symposium, October 1995

[4] Peters, Th.: „Purification of Landfill Leachate with Membrane Technology”, Water Quality International, pp. 23-26, 9.-10. 1996

[5] Peters, Th., "Past and Future of Membrane Filtration for the Purification of Landfill Leachate", Proceedings SARDINLA 99, Seventh International Waste Management and Landfill Symposium, Vol. II, pp. 367-374, October 1999

[6] Rautenbach R. \& Linn T., „Aufarbeitung von Konzentraten aus der Deponiesickerwasser-Behandlung mittels Nanofiltration“, Entsorgungspraxis, pp. 44-48, September 1995

[7] Reese, D.: "Verfahrenstechnische Optimierung von Umkehrosmosemodulen und anlagen für große Konzentrations- und Druckbereiche“, Fortschrittberichte VDI, Reihe 3, Nr. 537, Düsseldorf 1998 